\title{
Using Tabletop Robots to promote Inclusive Classroom Experiences
}

\author{
Isabel Neto ${ }^{1,2}$, Wafa Johal ${ }^{3,4}$, Marta Couto ${ }^{1,2}$, Hugo Nicolau ${ }^{1,2}$, Ana Paiva ${ }^{1,2}$, Arzu Guneysu ${ }^{4}$ \\ ${ }^{1}$ University of Lisbon, ${ }^{2}$ Inesc-ID, ${ }^{3}$ University of New South Wales, ${ }^{4}$ CHILI EPFL \\ \{isabel.neto,hugo.nicolau\}@tecnico.ulisboa.pt,wafa.johal@unsw.edu.au, \\ marta.couto@gaips.inesc-id.pt, ana.paiva@inesc-id.pt, arzu.guneysu@epfl.ch
}

\begin{abstract}
Geometry and handwriting rely heavily on the visual representation of basic shapes. It can become challenging for students with visual impairments to perceive these shapes and understand complex spatial constructs. For instance, knowing how to draw is highly dependent on spatial and temporal components, which are often inaccessible to children with visual impairments. Hand-held robots, such as the Cellulo robots, open unique opportunities to teach drawing and writing through haptic feedback. In this paper, we investigate how these tangible robots could support inclusive, collaborative learning activities, particularly for children with visual impairments. We conducted a user study with 20 pupils with and without visual impairments, where they engaged in multiple drawing activities with tangible robots. We contribute novel insights on the design of children-robot interaction, learning shapes and letters, children engagement, and responses in a collaborative scenario that address the challenges of inclusive learning.
\end{abstract}

\section{Author Keywords}

Visually impaired; children; human-robot interaction; shapes; haptic guidance; collaborative learning; accessibility.

\section{CSS Concepts}

- Human-centered computing Human computer interaction (HCI). Haptic devices; Accessibility; User studies; Empirical studies on accessibility; Accessibility systems and tools. Applied computing - Education, Collaborative learning; Collaborative interaction; Children,

\section{INTRODUCTION}

Learning shapes not only helps children to organize and identify information [35], it also is a vector for learning skills in multiple areas of the school curriculum, including reading, math, and sciences. Notably, an early step in understanding

Permission to make digital or hard copies of all or part of this work for personal or classroom use is granted without fee provided that copies are not made or distributed for profit or commercial advantage and that copies bear this notice and the full citation on the first page. Copyrights for components of this work owned by others than ACM must be honored. Abstracting with credit is permitted. To copy otherwise, or republish, to post on servers or to redistribute to lists, requires prior specific permission and/or a fee. Request permissions from Permissions@acm.org.

IDC '20, June 21-24, 2020, London, United Kingdom (C) 2020 Association for Computing Machinery. ACM ISBN 978-1-4503-7981-6/20/06 ..\$15.00 https://doi.org/10.1145/3392063.3394439

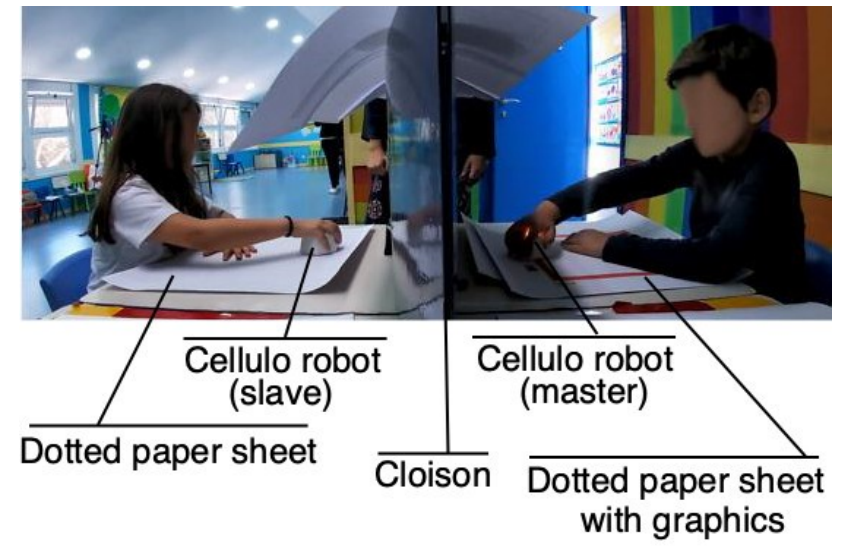

Figure 1 - Classroom experience with Cellulo.

a letter is to recognize their shape. This knowledge later aids children in learning handwriting, drawing, and geometry [39]. However, these activities mostly rely on visual representations of the shape and stroke dynamics (e.g., speed and direction), excluding children with visual impairments from acquiring essential spatial-motor coordination skills [39].

Previous research has explored the use of haptic feedback to support explorative learnings of geography [12, 15], geometry [42], and handwriting training for visually impaired persons $[32,33,39]$. However, they used costprohibitive devices. More recently, robots have been introduced in the classroom as a useful technology to teach visual-motor coordination such as geometry [17] and handwriting $[2,36]$.

Contrary to other interactive technologies, robots act in the environment; namely, they can move in space, opening novel opportunities for learning dynamic spatial information. Moreover, due to their feedback capabilities and inherently engaging nature, they have the potential to create truly inclusive environments where children with or without visual impairments can share technology $[21,22,25]$. Previous research has emphasized the need for collaborative activities to promote engagement $[35,37,41]$ and active learning $[10,11]$. Still, most assistive technologies such as raised-line maps or magnifiers support individual work in collaboration with teachers rather than inclusive work between peers in a classroom, such as educational smartphone games for blind children [23] or "McSig" a force-feedback device to teach handwriting $[32,33]$. 
In this paper, we used Cellulo [2, 31] to explore the potential of tabletop robots as an inclusive classroom technology. Cellulo is a haptic-enabled, small-sized robot that operates on printed sheets of paper (featuring a microdot pattern), which enables self-localization. Used with success with sighted children in multiple learning contexts, including geometry [17], physics [30], and chemistry [31]. To the best of our knowledge, we present the first study that investigates the use of tabletop robots in inclusive classroom activities. We conducted a qualitative study where we asked children with and without visual impairments to explore and identify geometric shapes and letters in a collaborative activity.

We address two research questions: (1) how the use of tabletop robots can help in inclusive and collaborative classroom activities with mixed-visual ability children, and (2) how the group dynamics changed, in small children in an inclusive environment, in any way due to this robot experience? Making two main contributions to this body of work: first, an analysis of the themes that emerged from a drawing and handwriting collaborative activity between children with and without visual impairments; second, design opportunities to inform the design of robot-assisted inclusive learning environments.

\section{RELATED WORK}

We discuss the related work in three fields of research: collaborative learning, teaching geometry and handwriting, and educational robots and assistive technologies.

\section{Collaborative Learning}

The inclusion policy in schools demands access (right to education) and equity (equal rights in education) for all children independently of their individual needs [14]. In the past years, there has been an increasing presence of children with disabilities in mainstream schools [21]. This trend for inclusive education brings challenges and opportunities for educational technology to adapt to children's needs, increase social engagement, and enhance collaborative learning scenarios $[21,22]$.

Collaborative learning engages pupils in educational tasks, coordinating actions to achieve the same shared goal [11] While a whole set of research investigates how technology can help build this shared understanding (CSCL), groups of learners with and without visual impairments face the problem of not sharing the same sensory perception of the task. These differences can make perspective-taking and grounding hard to reach for such mixed groups, so using multisensory interactions can be beneficial [6]. Despite these challenges, several studies demonstrated that collaborative learning could be successful in children with or without visual impairments. For example, Thieme et al. [36] leveraged tangible interfaces to promote collaborative learning of computer programming. Tanhua-Piiroinen et al. [35] used a force-feedback device in a pair-based experience to support explorative learning of the solar system and earth geography. Additionally, Reid and Plimmer [32, 33] explored a collaborative approach where teachers instructed people with visual impairments in handwriting using forcefeedback technology. In our work, we designed a pair-based exploration game of shapes and letters for children with and without visual impairments using a tabletop robot.

\section{Teaching Geometry and Handwriting}

Drawing of geometrical shapes, such as circles or triangles, is taught at a very young age in preschools $[2,42]$. With this, students improve their visual-motor coordination skills, a prerequisite to learning handwriting [42]. Literacy skills start to develop early on, and at the age of three, children can produce some letter-like forms and draw with a purpose, constructing concepts based on symbols, developing tactile acuity and communication skills, also crucial abilities for children with visual impairments [40].

Children usually learn letters in the first year of primary school, where sighted children learn cursive handwriting, and visually impaired children traditionally learn print letters and Braille [32].

Despite its importance in daily life, Metatla et al. [22] study showed that adults with visual impairments still experience difficulties in signing and filling forms, so in our study, we decided to use a learning experience based on spatial concepts and handwriting.

\section{Educational Robots and Assistive Technologies}

New interactive techniques are rising, and researchers are exploring how different types of feedback like haptic, tactile, sound, and visual might be useful in HCI as assistive technologies [22]. Furthermore, the physical embodiment of robotics has promoted a surge in the use of robotics in education and as assistive technologies.

Robotics for education can follow two distinct approaches. The first one, robots, are used as social entities that interact with learners supporting the learning activities proactively. In this context, such social robots can play roles such as that of a tutor or teacher, peer, or novice, in the learning activity [4]. Different areas of application have been explored, such as language learning [5], mathematics [18], sustainable development [1], writing skills [8], and others. Social robots are also extensively used for assisted therapy for autism spectrum disorders [34, 38]. The second approach on robotics for education considers robots not as social entities that interact with learners, but rather as tools to support learning in the activities or learning by doing, for example, robots to be used for learning how to program $[3,13,24,26]$.

In this paper, we follow the second approach regarding robots as tools to be used for providing feedback in inclusive learning activities.

Although there have been previous attempts to use robots in educational settings for visually impaired children, these were limited to teaching computational thinking $[3,24]$. In most studies, robots serve as haptic output devices that render programming instructions either from a screen-based environment [24] or tangible objects $[3,26]$. To the best of 
our knowledge, robots were never explored as input/output tools to learn geometry and handwriting skills in mixedvisual abilities groups.

Haptic feedback has two significant characteristics that are useful for developing the skills needed for learning geometry and handwriting [29, 32, 39]. In essence, 1) they allow the user to feel the shape and spatial characteristics of the drawing (the grapheme), and 2) they can be used to guide the hand during the drawing activity (the ductus). In this paper, we leverage the ability of robots to move in space and use them as an assistive technology to input and convey spatial information related to hand drawings.

\section{METHODOLOGY}

All the children involved, and school staff voluntarily agreed to participate in the study. Parents and teachers gave their informed consent for all the sessions. Children gave their assent.

\section{Participants}

Our exploratory evaluation involved 20 pupils; the selection was made based on the following criteria (1) last year of preprimary school, or from primary school (2) pairs were created with children from the same classrooms. The number of girls $(\mathrm{N}=7)$ was lower than boys since there were more boys in these classrooms. Among them, four participants had different degrees of disability: one child with low vision since birth; two children had a low vision due to disease and one child with multiple developmental impairments (cognitive, language, and motor skills delays). The average age of participants was 6.6 (SD: 1.1) years old, and six of the children were in primary school (and are familiar with letters), while the other 14 were in preschool.

Children knew each other, and none of them had any previous experience with robots. They worked in pairs matching children from the same classroom (primary school or pre-primary school), with no other predefined selection (based on age, friendship, or gender), Table 1 shows the different pairs.

\begin{tabular}{|c|c|c|c|c|}
\hline $\begin{array}{l}\text { Kids } \\
\qquad \begin{array}{c}\mathcal{E} \\
\text { Pair }\end{array}\end{array}$ & Age & Gender & Visual Acuity & $\begin{array}{l}\text { Additional } \\
\text { information }\end{array}$ \\
\hline $\mathrm{C} 1$ & 8 & $\mathrm{~F}$ & $\begin{array}{l}\text { Profound low } \\
\text { vision } \\
\text { (VA 0.025) }\end{array}$ & $\begin{array}{l}\text { from birth, } \\
\text { primary school }\end{array}$ \\
\hline $\mathrm{C} 2$ & 8 & M & sighted & primary school \\
\hline $\mathrm{C} 3$ & 10 & M & $\begin{array}{l}\text { Moderate low } \\
\text { vision } \\
\text { (VA } 0.25)\end{array}$ & $\begin{array}{c}\text { Since } 6 \text {, primary } \\
\text { school }\end{array}$ \\
\hline $\mathrm{C} 4$ & 8 & $\mathrm{~F}$ & sighted & primary school \\
\hline C5 & 6 & M & sighted & preprimary \\
\hline C6 & 6 & M & sighted & preprimary \\
\hline $\mathrm{C} 7$ & 6 & $\mathrm{~F}$ & sighted & preprimary \\
\hline $\mathrm{C} 8$ & 6 & M & sighted & preprimary \\
\hline
\end{tabular}

\begin{tabular}{|c|c|c|c|c|}
\hline $\begin{array}{l}\text { Kids } \\
\& \\
\text { Pair }\end{array}$ & Age & Gender & Visual Acuity & $\begin{array}{c}\text { Additional } \\
\text { information }\end{array}$ \\
\hline C9 & 6 & M & sighted & preprimary \\
\hline $\mathrm{C} 10$ & 6 & M & sighted & preprimary \\
\hline $\mathrm{C} 11$ & 6 & M & sighted & preprimary \\
\hline $\mathrm{C} 12$ & 7 & M & sighted & $\begin{array}{c}\text { cognitive, language } \\
\& \text { motor delay, } \\
\text { preprimary }\end{array}$ \\
\hline $\mathrm{C} 13$ & 6 & M & sighted & primary school \\
\hline $\mathrm{C} 14$ & 7 & $\mathrm{~F}$ & $\begin{array}{l}\text { Moderate low } \\
\text { vision (VA } \\
0.16)\end{array}$ & $\begin{array}{c}\text { Since 4, primary } \\
\text { school }\end{array}$ \\
\hline $\mathrm{C} 15$ & 6 & M & sighted & preprimary \\
\hline $\mathrm{C} 16$ & 6 & $\mathrm{~F}$ & sighted & preprimary \\
\hline $\mathrm{C} 17$ & 6 & M & sighted & preprimary \\
\hline $\mathrm{C} 18$ & 6 & $\mathrm{~F}$ & sighted & preprimary \\
\hline $\mathrm{C} 19$ & 6 & $\mathrm{~F}$ & sighted & preprimary \\
\hline $\mathrm{C} 20$ & 6 & M & sighted & preprimary \\
\hline
\end{tabular}

Table 1. Summary of participants (VA for visual acuity)

\section{Material}

We selected the Cellulo robots based on the following features: (1) haptic guidance with accurate localization [31]; (2) visual and tactile feedback; (3) small-sized, and easy to handle, (4), low-cost solution that operates on printed sheets of paper (based on microdots pattern that enables selflocalization). Cellulo is a versatile tool used in different learning contexts (geometry, physics, and chemistry) [17, 30, 31]. For instance, Asselborn and Guneysu et al. [2] showed that these robots can be used to teach as traditional handwriting learning methods for sighted children and were particularly interesting to teach the ductus and could adapt for children presenting visuomotor coordination issues [16].

In our experiment, Cellulo illustrated the shape via haptic feedback; it guided the children's hands through the shape, rendering the trajectory that draws the shape (its ductus). Cellulo can exert a force of about $1 \mathrm{~N}$, which is not enough to drive the hand of children but enough to guide their hand [31]. Cellulo also used visual feedback, with different colours of LEDs, allowing both children with and without visual impairments to see the robot moving. Children were free to decide what type of feedback they wanted to use, as some information was redundant across different modalities. For example, when Cellulo would start moving (haptic and visual feedback), it would also play a 'beep' (auditory feedback) and have its LEDs change from Blue to Yellow (visual). As the Cellulo robots do not present speakers, the tablet controlling the robots played the sound. Figure 2. presents the different elements used in the experiment. Each pair of children had two robots connected via Bluetooth to a central tablet used to control the activity and set the shape children on which were working. 
For the experiment, we printed eight maps: 7 were showing the different shapes used in the experiment (Figure 2), and one was blank for when students had to guess the shapes from the robot's motion on the paper.

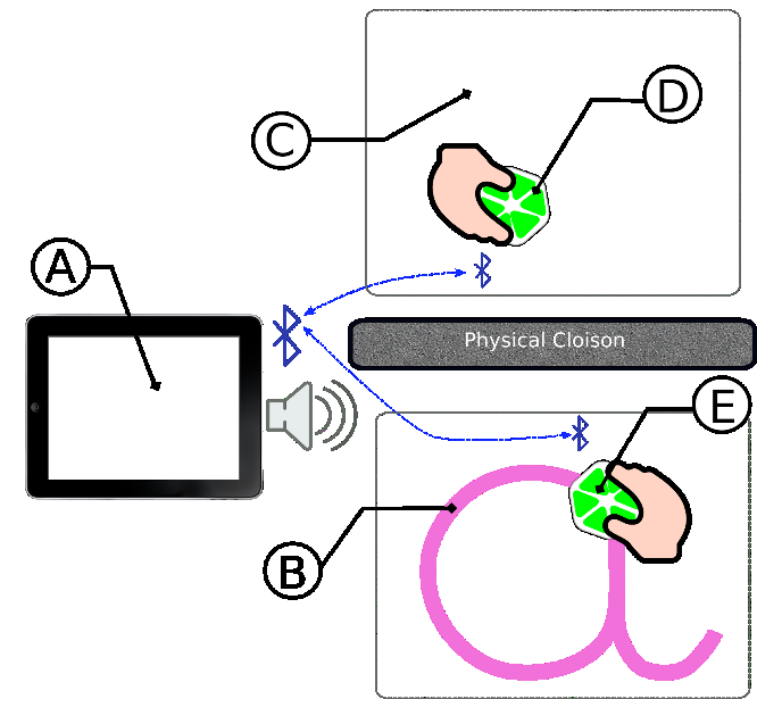

Figure 2. Setup with the material used for the experiment. (A) An Android tablet used to control the robot's mode (quiz or guess), to select the shape, and to play a beep sound at the start and the end of a stroke. (B) The graphical visual feedback printed on the dotted map, here the letter ' $a$ '. (C) A blank map with the microdots pattern for localization. (D) The slave Cellulo robot that mirrors the master robot. (E) The master Cellulo robot with 6 LEDs used to signal the start and the end of a stroke.

\section{Procedure}

A week before the study, all the students involved had a lesson reviewing the geometric forms: circle, square, and triangle, and letters "p" "a" and "i" with their teachers.

Before the study, we asked the teachers to describe the participants' social relations, stating best friends and close groups. We used this to measure the impact on social relations in the day after the study.

The study took place in a classroom, and each session lasted, on average, 30 minutes. Before the session, researchers reorganized the space to arrange two different areas with a wide-angle camera capturing children's interaction. They recorded children's faces, hands, and the robots' movement, as illustrated in Figure 1. Five researchers and two teachers were always present during the sessions. One researcher monitored the robots (e.g., replacing the robots when the battery was low), the other four were assigned, in pairs, to one of the two tables. Teachers were instructed not to interact with children. Their role was to observe and to take notes during the study.

In these sessions, children were sitting facing each other but could not see or touch each other's workspace (Figure 1). Each session had a learning task (draw a circle) and a quiz based on shapes and cursive letters, in the following order: square, triangle, house, "p", "a" and "i" (see Figure 3 on the drawings used). These shapes were selected to understand the impact of multiple strokes in the activity.

At the beginning of the session, we told children that they would be using small robots to take turns drawing and guessing shapes. After showing the robots, we asked them to practice drawing with it. They followed the path printed on paper (cf. Figures 3) and drew circles using the robot feedback available (visual, tangible, sound, and haptic).

For the following drawings, we alternated between a quiz and a guessing mode. On quiz mode, for the 'house' and "i" maps, children guess the shape and discuss with each other until they reach an agreement, for this task, both robots draw the same shape on blank maps. The centralized app running on the tablet autonomously controlled both robots during the quiz. In the guess mode (used for square, triangle, "p" and "a " maps), one child was handling the master robot and the other one the slave. The master robot was put on passiveassistive mode to move smoothly on the paper sheet. The slave robot mirrored the speed and path of the master robot. The child holding the master would have a paper map displaying the graphics, whereas the child holding the slave robot had a blank sheet of paper but had to guess the shape from her robot's movement.

The order of the tasks was the same for all participants: square and triangle shapes for the first two tasks of the childbased mode; the house, for the robot-based mode; "p" and "a" letters for the child-based mode, and the " $i$ " for the robotbase mode. The last task was a free drawing task where we asked each child to draw a shape of their choosing for their partner to guess.

During the tasks, researchers could help the children by providing some predefined clues, and at the end, they could draw the shape on the child's back. In the robot-mode task and drawing tasks, children gave tips as they wished, drew on the backs of their partners, and talked aloud about what they were doing. We scripted these tips to ensure that all the pairs had similar information.

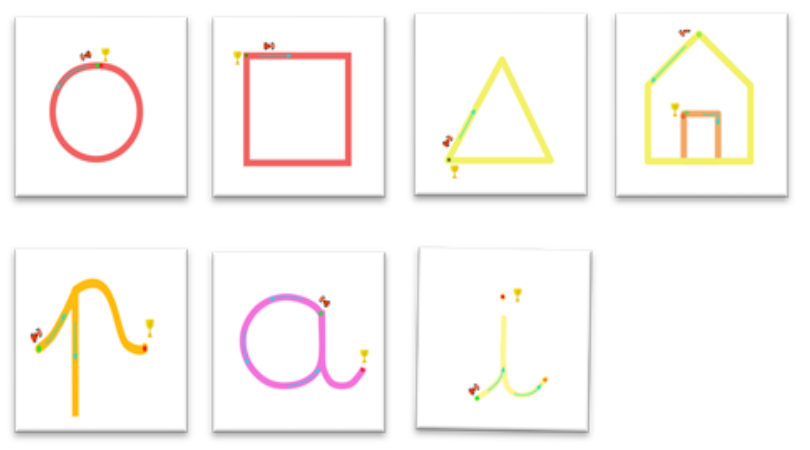

Figure 3 - Printed sheets of paper used for the study $(42 \mathrm{~cm} \times 42$ cm) 
When the session ended, we asked them to use a pencil to draw all the shapes (except for the free drawings). Next, in the debriefing stage, children were asked to give their impressions about using the robots, what were the easiest and hardest tasks, and how they would like to use robots.

We also debriefed the two teachers, who were in the room during the whole session as observers, by asking them about the social interactions, engagement with the robots, task adequacy, main challenges, and overall opinion on the session. The day after the study, we asked the teachers to report whether they noticed any differences in social relations between the children. We explicitly asked them to make this assessment in three situations: when children arrived at school, during playground time, and in the classroom.

\section{Data capture and analysis}

All sessions were video and audio recorded (circa 10 hours). Two researchers conducted a thematic analysis using a scheme based on Meier et al. scheme for assessing the quality of collaboration processes [7, 20], following a grounded approach to identify new codes and emergent themes in the data from the sessions' observations and teachers' feedback. The Cohen Kappa [19] was .56 for $18 \%$ of the data, which corresponds to a moderate agreement in coding.

The following metrics were computed based on observation and robot logs. (1) NumFB - the average number of times each feedback is selected. (2) TTask - average time spent, in minutes, at each task. (3) NRoundTask - the average number of robot rounds per task. (4) MinD - minimal path distance: average minimal distance between each robot's position recorded and the actual shape (without considering temporality). (5) NTaskSucessFB - number of successful tasks split by feedback.

Plots of the robot drawing, based on logs, were also visualized, as shown in figure 4 .

\section{FINDINGS}

We structured our finding according to the emergent themes: robot interaction (sub-themes: accessibility. Capacity to manipulate and explore; perceived feedback quality; coherence between available feedback; and children responses to the robot), collaborative and inclusive learning (sub-themes: individual and pair engagement; roles and task division perception for children, robots and researchers; pair interaction - coordination; request for help/ giving help; dialogues; inclusive behaviour), and activity experience (sub-themes: the complexity of the task; previous knowledge to do the task; task performance ductus, flow; creativity). For each, we present insights and design opportunities.

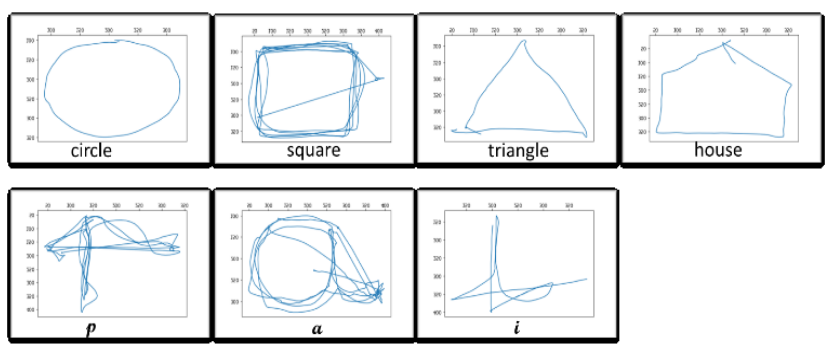

Figure 4 - Plots of predefined shapes based on robots' logs

Robot Interaction and feedback

As a tabletop robot, Cellulo designed for group work. It allows all children, regardless of visual impairments, to use the same robot in the same way, promote collaboration and cooperation between them.

\section{Cellulo as an assistive supporting tool}

Our participants $(\mathrm{N}=20)$ were able to interact with the robots by themselves, independently of the role they had (drawing role, guessing, or guessing in pairs), or if they had any impairment (visual, motor or cognitive). This fact suggests that Cellulo copes with the principles stated by Mynatt et al., [27, 28] and Winberg [41] for assistive tools. (1) Access to functionality: all actions available to a sighted child were also available to a child with visual impairments. (2) Enable manipulation and exploration, allowing interaction and sharing a collective state of things. (3) Be coherent in all interfaces (visual, haptic, tactile, sound) and between common resources (for instance, precise mirroring between robots). Children with (mean: 2.33, SD: 0.33) and without visual impairments (mean: 1.85, SD: 0.46), responded correctly using the robot's feedback (3 shapes and three letters).

These numbers suggest that the visual acuity of the child did not influence pair performance, meaning that Cellulo was able to be an assistive and inclusive supporting tool.

When calculating NumFB - number of times children selected each feedback, we observed that, although haptic feedback was available, sighted children $(\mathrm{N}=17)$ tend to use visual feedback more often, (mean: 5.23, SD:0.85) in comparison to haptic feedback (mean: 4, SD:1.16). For children with visual impairments $(\mathrm{N}=3)$, as expected, the most used feedback was haptic (mean: 12.33, SD:2.02), but children with low vision also used visual feedback (mean: 1.67, SD: 0.88).

Speed and strength applied to draw is essential for understanding the shape

Children felt a friction force when drawing with the robot. In the first task, drawing a circle, all children were trained to know how to draw with the robot. Computing the TTask and the NRound, we found that, for the circle task, some of the children took more time than others to tune the speed and strength needed to draw with the robot, TTask for the circle (mean: 2:05, SD: 1:02) and NRound for the circle (mean: 3,8 , SD: 2:15). We also noticed these differences in other tasks (square, triangle, house, $\mathrm{p}, \mathrm{a}, \mathrm{i}$ ), the average rounds, in 
those, Square Triangle House "p" "a" "i", were NRound (mean: 2,58, SD:1:20), and the time spent TTask, for Square Triangle House "p" " a" "i", (mean: 2:22, SD:1:01). The speed of the drawing influenced children's guessing, there were many pauses, the movement was not fluid, and as observed, this made it harder for their partner to perceive the shape correctly.

\section{A clear notion of the starting and endpoint of the drawing}

Another observable behaviour was the children not stopping when they reached the end of the shape and continued drawing. This behaviour could have multiple explanations, namely the difficulty in understanding the partner's perspective or perceiving the end of the shape. They did not understand that repeatedly drawing the shape was not helpful for their partner. One example of this difficulty is $\mathrm{C} 1$, during the house task when she said to the robot, "Hey, stop moving!"(C1)

Robot's sound can be a facilitator when used in-context One child, based on robot sound, guessed it was a car "sounds like a car" (C13) during the free drawing. Although the robot played different sounds in specific phases (starting point, change of the stroke), none of the children understood them. These observations suggested that audio feedback when used at the right time and accordingly with children's expectations (e.g., sounds of the objects or small words), can be a facilitator, but can also be confusing or even ignored if unexpected.

\section{Dealing with multiple strokes}

Non-continuous flow drawings need multiple strokes, like the door in the house, or the overlapped stroke in the letter "a". When changing strokes, the robot's lights (in the upper side of the robot) switched to green and played a specific sound. Children did not perceive it, even after the researchers called their attention to the lights and sounds. Children could not see the lights when using haptic feedback, as their hands were on top of the robot, however even when they used visual feedback (observing the robot moving without holding it), they also ignored these clues. As observed, for all participants, the robot design for changing strokes is still an open challenge and was very confusing, as illustrated in figure 5 and 6 . Also on the dialogues during the experience, as in "i" task, when the robot changed strokes to draw the dot, C4, using visual feedback, said "it is strange it always moves at the end! [without noticing any change on sound or colour lighting]" (C4).

\section{Children responded to robots with curiosity and tenderness}

Children were interested to know how the robot moved and if it could see, who was the robot owner or even if they could get one for themselves. Playing with the robot during the session was observed in all the children. Two girls ( $\mathrm{C} 1$ and C4) held the robot in their chest during breaks with tenderness.

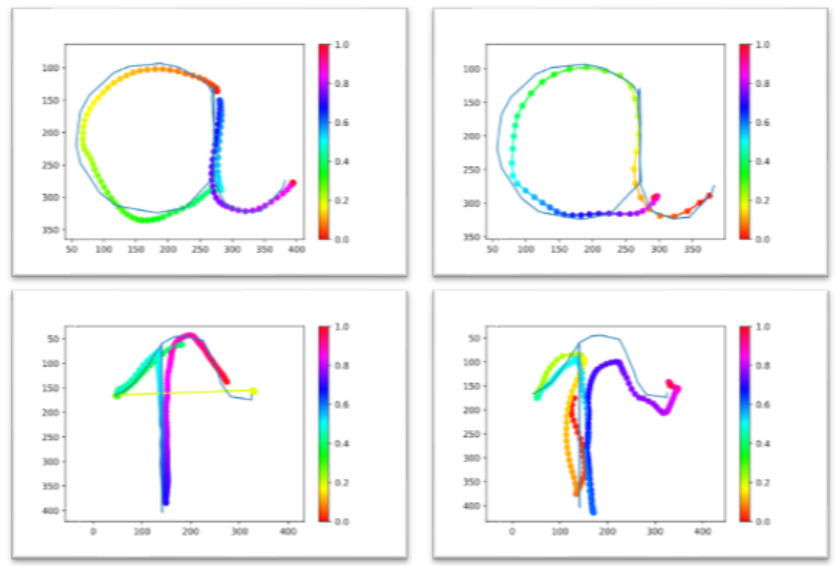

Figure 5 - "p" and "a" Plots are showing the challenge of overlapping strokes (the vertical strokes of each letter). The colour gradient illustrates the temporality of the drawing, with 0 being the first point recorded and one the last.

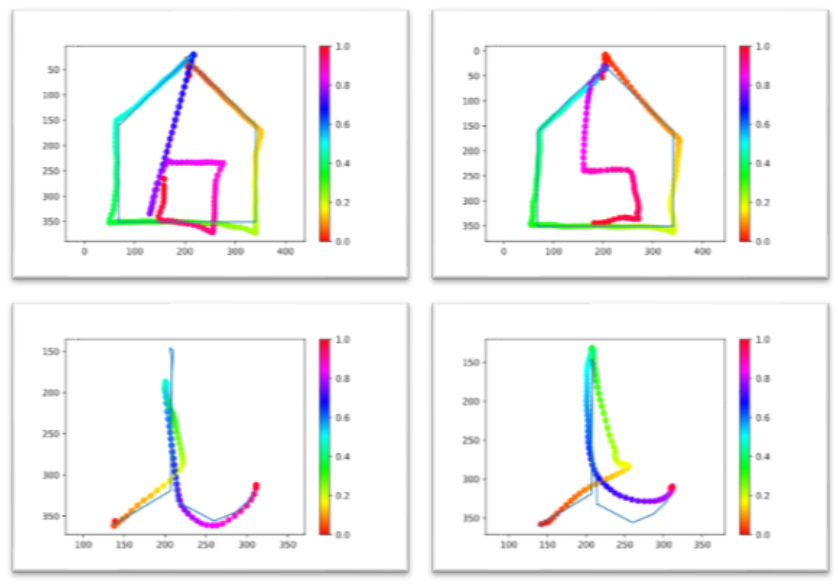

Figure 6 - "house" and "i" Plots are showing the challenge of multi strokes (for drawing the door's house and drawing the dot of the i). The colour gradient illustrates the temporality of the drawing, with 0 being the first point recorded and one1 the last.

A Collaborative and inclusive learning experience The assessment made by the researchers and teachers present during the session was that all children $(\mathrm{N}=20)$ were collaborating during the experiment. We did not observe any influence of their visual acuity in the interaction. Children responded with high engagement and in an inclusive way.

We recorded more than 500 interactions between pupils and robots; the level of engagement and interest was high, in these interactions we observed negotiation, collaboration, dialogues, and a clear division of roles and responsibilities. These observations suggest that the experience was collaborative and inclusive and that children perceived the robots as a supporting tool. Considering the pairs $(\mathrm{N}=3)$ with and without visual impairments, teachers reported that the collaboration was very high, and two of the dominant children had visual impairments (C1 and $\mathrm{C} 7)$. 
We used the following dimensions to evaluate the quality of the collaboration: mutual understanding (roles, task divisions \& time management), dialogue management, information pooling, reaching consensus and reciprocal interactions, and individual tasks orientation.

Mutual understanding, roles, task divisions, and time management

Pupils had a clear understanding of their different roles, as well as for the robot. For example, in a pair's dialogues which $\mathrm{C} 3$ and $\mathrm{C} 4$ discussed the role of the robot in the "free drawing" task and aligning the beginning of the tasks.

$$
\begin{aligned}
& \text { (C3) - "Are we using the robots to draw?" } \\
& \text { (C4) - "Of course, it is with the robot, if you do not use } \\
& \text { the robot, how can you guess what I am drawing?" } \\
& \text { (C3) - "ok, you can start?" }
\end{aligned}
$$

\section{Dialogue Management was common}

With different goals: to negotiate and get consensus, request for help, or just to establish a good relationship with researchers, talking about other things not related to the experience or even to talk with the robot. $\mathrm{C} 1$ from pair 1, in a negotiation phase, in the "house" tasks, moved twice to the side of the partner and whispered in his ear to influence the partner. The same child, in the "i" task, requested help from his partner, C2, about cursive letters (they are both in the 2 nd year of primary school).

$$
\begin{aligned}
& \text { (C1) - "I do not know cursive letters." } \\
& \text { (C1) -" [talked with (C2)] but you learned it in the first } \\
& \text { year." }
\end{aligned}
$$

One other student started a dialogue to create empathy with the researchers during a break, one of the researchers was French so when $(\mathrm{C} 4)$ noticed it, she started a conversation speaking a few words in French. "Bonjour.".

\section{Information pooling, children used different types of help}

Such as to request to repeat, clues or drawing the figure on the other's back. "Guesser Frequently asked their partner to repeat the movement, "can you do it again?" (C8), Clues could be related to the context, as the case of $\mathrm{C} 2$ (pair 1) in the free drawing.

$$
\begin{aligned}
& \text { (C2) - "it flies [the first clue provided to C1]" } \\
& \text { (C2) - "can take } 2 \text { or } 3 \text { persons inside [second clue]" } \\
& \text { (C1) - "it is a helicopter [C1 tried to guess]" } \\
& \text { (C2) - "I am going to do it again [repeat case]" } \\
& \text { (C1) - "It is an Air Balloon [child gave the correct } \\
& \text { answer]" }
\end{aligned}
$$

In another case the clue was related to the sound of the letter, this was made by $\mathrm{C} 14$, in task "p", "rhymes with b, $d$ [giving help to his partner, C13 could not guess and gave-up]" (C14)

In all sessions, there were a total of 120 instances of help provided by researchers and children, clues $(\mathrm{N}=91)$, and drawing on the backs of the children $(\mathrm{N}=29)$.
In the free drawing tasks (where researchers recommend children to give each other help), in a total of 20 free drawings, children gave help in $3 / 4(\mathrm{~N}=15)$ of the sessions.

\section{Reaching consensus and reciprocal interactions}

Children negotiated, influenced, and in most cases, reached a consensus by themselves in robot-based tasks. During the negotiation, one of the students suggested some answers, and the other confirmed. However, it was not always the case, and sometimes they did not reach a consensus. One example was pair 1, in the "house" tasks, where C1 tried to influence C2 (moving beside him).

(C2) - "[C1 moved beside C2 to influence]it is a rectangle."

(C1) - " and I think it is a rectangle too."

(researcher) "it is similar to a rectangle [C1 return to his workplace and robot did a new drawing]"

(C2) - "[C1 moved again to the side of C2 to influence] he told that it is a house, but I am not convinced."

(C1) - "[researchers draw a house in each student's back] it can only be a house."

(C2) - " It does not seem like a house. Maybe it is a building. I do not agree with her [and they did not reach an agreement]"

\section{Pair coordination and individual task orientation}

Children had a clear perception of the common goal. They worked together to sync the robot's movement, to negotiate, or to celebrate. When they found out the correct figure, they gave positive feedback to each other: "we did it" (C5), "good, well done." (C6). Even when there was an individual task orientation to learn something new, like the ductus or the form of a cursive letter, a pair orientation observed as shown in the task "i" by $\mathrm{C} 1$ :

(C1) - "[ She tried to learn the ductus and the format of " $i$ " based on drawing with her finger, in the paper. She also proposed a solution for the flow to be perceived] it is better if we start here and then do this".

\section{Activity Experience}

In $80 \%$ of the cases, pairs found out the form, independently of the visual acuity of each participant, and a third of them only used robots for that.

Age influenced the results

The age of the child influenced the ability to do the tasks. Children learn drawing of geometrical shapes such as circle or triangle at a very young age in preschools [2, 42]; however, we observed that pupils in preschool were not familiar with the letters (even if teachers had practised these letters with them before the study), one of these students did not recognize the triangle. 


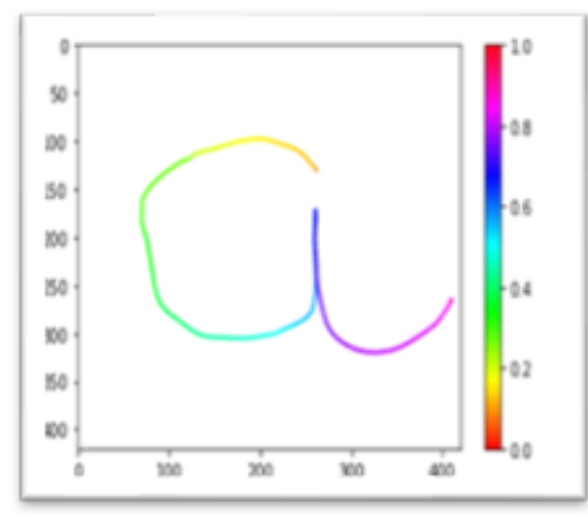

Figure 7 - Example of a correct ductus. Plot based on Robot logs for the letter "a". The colour gradient illustrates the temporality of the drawing, with 0 being the first point recorded and one the last.

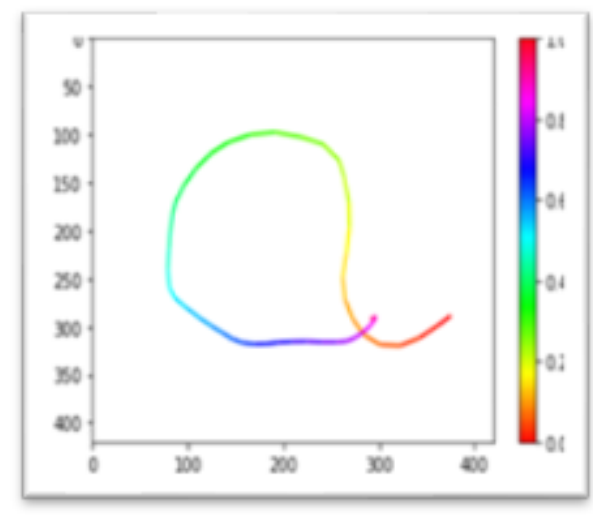

Figure 8 - Second example, showing an incorrect ductus. The child started in the wrong place. Plot based on Robot logs for the letter "a". The colour gradient illustrates the temporality of the drawing, with 0 being the first point recorded and one the last.

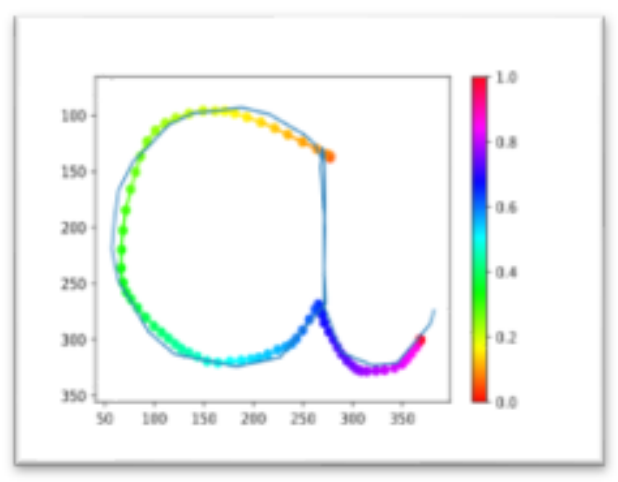

Figure 9 - The third example is showing an incomplete ductus of an "a", plot based on Robot logs The red dots show the trajectory of the drawing, in this case, the child drew two times the letter, in both of them he did not draw the vertical stroke.
Cursive letters awareness

One factor noticed and confirmed by children with visual impairments $(\mathrm{N}=3)$ was that they did not learn cursive letters, only print letters and Braille.

(C14) - " We are used to drawing in print letter format, not in the manuscript."

However, these students were curious about cursive lettering, and they used this format in the posttest evaluation. One example was with the letter " $p$ " in pair 1, where C2 helped $\mathrm{C} 1$ (with VI) to learn cursive letters (giving clues and drawing in the $\mathrm{C} 1$ 's back).

(C2) - "[C2 gave a clue to C1] it is in the manuscript format."

(C1) - "[C2 draw "p" in C1's back in print] I draw the $p$ like this."

(C1) - "can I see the letter $p$ ? [and looked to " $p$ " in the paper-figure 2 and draw the letter with his finger to get it memorized",

Ductus Quality and temporality

We noticed that the quality of the ductus and the temporality influenced the perceived shape. Based on robot's logs (Figure $7,8,9)$, the first plot showed a good temporal drawing of "a", the second showed an incorrect shape due to a wrong starting point, and the last plot showed an incomplete ductus.

Some interesting findings were noticed: (1) in letter p, 32 rounds made, 21 had a correct and complete flow, seven were incomplete, and 4 had a wrong ductus. 6 children answered correctly (from those only pair 8 , had no additional help). The speed of the drawing was too fast in 4 rounds ( 2 per each child, C2 and C4). (2) For the letter "a", in 34 rounds made, 15 had a correct and complete flow, nine were incomplete, and 10 had a wrong ductus. Seven children answered correctly (from those three pairs had no additional help, pair 4,8 , and 9). The speed of the drawing was too fast in 4 rounds $(\mathrm{C} 1, \mathrm{C} 4$, and $\mathrm{C} 10)$ and too slow for three rounds of (C9).

The letter "a" was only drawn correctly half the time. The number of correct answers was higher than "p". Suggests that "a" was more natural to be perceived when drawn by a robot. Even when trajectory was incorrect or incomplete, perhaps due to the circular shape and because "a" is a familiar vowel.

\section{Task Complexity}

Letter " $i$ " was the shape with the highest number of clues ( quare $=3$, triangle $=4$, house $=32, \mathrm{p}=15, \mathrm{a}=12, \mathrm{i}=34$ ) and " $\mathrm{a}$ " was the shape that had the highest average of rounds ( quare $=2$, triangle $=1.6$, house $=2.8, \mathrm{p}=3.2, \mathrm{a}=3.4, \mathrm{i}=2.5$ ).

When calculating MinD - minimal path distance between each robot's position recorded and the actual shape, the distance was (in order from highest to lowest): drawing a shape (house) $>$ letters $(\mathrm{p}>\mathrm{a}>\mathrm{i})$ and basic shape (circle, square and triangle). The MinD value suggested that "p" and "a" had a more complex trajectory than "i", maybe due to stroke overlap (in " $\mathrm{i}$ " the dot is a separate stroke). Children 
followed the same complexity order independently of their visual acuity.

\section{Feedback efficiency}

The NSuccessFB - an average of success tasks (guessed shape or the letter) split by feedback and visual acuity used, was computed for tasks (square, triangle, house, "p", "a", and " $i$ "), each child had to guess 4 of those. On average, the child answers with success 2.9 times out of 4 .

The plot in figure 10, presents the feedback used in all successful tasks split by visual acuity. Overall haptic feedback was more efficient than visual (even for sighted children), visual feedback was never used with success by a low vision child (even for child $3-C 3$ with a $\mathrm{VA}=0.25$ ). A blend of the four types of feedback (visual, haptic, audioclues and back feedback) ) performed better (52\% for sighted and $85 \%$ for $\mathrm{VI}$ ) than using only visual or haptic feedback.

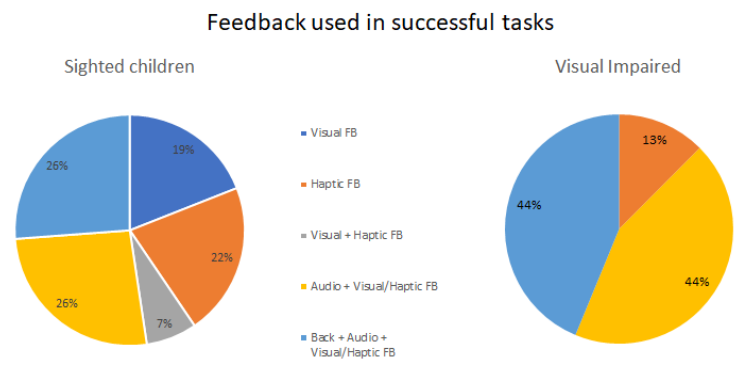

Figure 10 - Two pie charts showing the feedback split in successful tasks by visual acuity.

These metrics suggest that, for this study, the combination of feedback types, namely adding audio (provided by clues) and back feedback (drawing on the back), performs better than using only one feedback at each time. Independent of the visual acuity of the participant. For this table-top robot, the most efficient interaction was on haptic.

Several children's responses to the activity: satisfaction, confusion, frustration, comfort, engagement, creativity, imagination and perceived expertise

We noticed children's satisfaction when they completed the tasks at a pair level, as illustrated by $\mathrm{C} 2$, in the free drawing activity.

$$
\begin{aligned}
& \text { (C2) - "[C1 drew a unicorn] it is a unicorn wow." } \\
& \text { (C2) - "she is my "sister" and loves unicorns." }
\end{aligned}
$$

Confusion leading to frustration was also observed in children whenever they did not remember the shape previously drawn, or they did not understand the shape; as shown by $\mathrm{C} 1$ while guessing "p". " [after the first round] Really. [she was baffled and frustrated]" (C1)

Comfortable and Engaged with the robot: we observed that $\mathrm{C} 1$ and $\mathrm{C} 13$, both with low vision, were very close to the robots, showing that these children did not have any fear of the robot even when he was moving.
Creativity: during free drawing activity, children were very creative, regardless of the capabilities of the robots. They drew unicorns, hearts, dragons, air balloons, stars, princesses, chairs, volcanoes, cars, people, animals, sun and sea. In the free drawing, children had already experienced the robot's difficulty in drawing angels and multiple strokes; however, that did not influence their ideas. Looking for the plots produced by the robot logs, it is challenging to recognize more complex drawings, as we can see in figure 11. Regarding imagination, we asked children how they could use robots in the future. Children had many suggestions; for example, they said they could use the robots to play remotely (children in different houses playing together) or to play with friends and family. They mentioned using robots based on stamps to draw complex figures and help visually impaired children to be more creative. They also mentioned learning other figures and drawings, and even to cook dinner (the problem immediately found by $\mathrm{C} 16$, was that they would need arms).

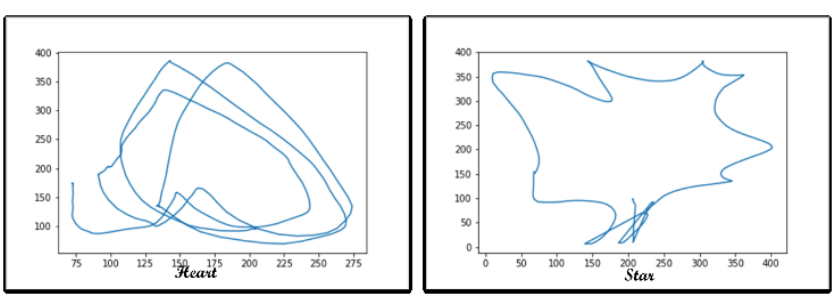

Figure 11 - Two plots based on Robot logs for the free drawing, showing a heart and a star

Perceived robot expertise, one example was made by pair seven that said, "robot knows how to write" (C13) and "better than us" (C14).

\section{Posttest evaluation:}

At the end of the experience, we asked students to draw all the figures they learned during the session, they all did the six figures correctly $(\mathrm{N}=20)$, and all visually impaired children tried to do the letters in cursive format $(\mathrm{N}=3)$.

To address our second research question, we asked teachers to evaluate participants' social relations the day after the experiment in three situations: at the time of arrival at school, in the classroom, and during the playground. Teachers did not identify any changes in social relations after the session. This fact suggests that one experience with these robots did not make an impact on social dynamics. In future studies, it would be interesting to evaluate the impact of a multi-time experience in the social engagement between participants.

\section{DESIGN OPPORTUNITIES}

Design opportunities for Learner-Robot Interaction

From our analysis, we identified opportunities for the design of inclusive robots that support drawing activities. Adapt haptic force feedback to each child; the strength of the haptic could be adaptive to the child to improve the speed and flow of the drawing. New ways to represent the starting and ending points of strokes and traceability of robots' 
actions such as magnetic drawing tables or textures are challenges to address in the future.

\section{Design opportunity for Collaborative, inclusive scenarios}

We observed that all the pairs, with and without visual impairments, engaged in collaborative behaviours. Our study showed potential for pairs of learners. One idea for future studies could be classroom work, with a common goal to create a solar system. Each pair would draw, design or represent, with robots, the sun and each planet (with specific features such as planet rotation speed, orbit, size, and temperature). In the end, all students would jointly create the solar system placing the planets in the right order and moving in the correct plane orbit. Cellulo could localize in the correct orbit based on its capability to self-orientation and configure its velocity based on each planet's speed. Another activity to explore navigation skills, essential for visually impaired children, could be using robots to create a school representational map based on mixed-abilities pairs to represent classrooms, canteen, playground, and stairs.

\section{Design opportunities for School activity}

During our sessions, we observed that when drawing on childrens' back, guessing was faster and more accurate. Future research should explore Audio and haptic back feedback (using, for instance, Rovables robots [9]). Results suggest that these two types of feedback are well perceived. An additional opportunity to explore is the use of robots to promote creative work, especially in visually impaired children. For instance, integrating painting software to create digital pictures (or stamps), and using force haptic of the robot to help visually impaired children to draw more complex figures.

\section{CONCLUSIONS AND FUTURE WORK}

Inclusive, collaborative learning experiences are challenging to design. With this paper, we tackle this challenge, answering our research questions and presenting how we design and implement the first field study of such learning activity using robots. Shared results, finding and design opportunities for future research in this area.

While designing for keeping inclusive collaboration in mind, we discovered new challenges such as the rendering of multi and overlapped strokes, ductus and speed, and identification of reference frames.

The small number of pupils involved and the "novelty effect" of the used system did not allow us to assess the learning effect of this experience or the impact on the social dynamics of the small children. However, the qualitative analysis revealed positive engagement and collaboration between students with and without visual impairments.

With this study, we demonstrate the applicability of tangible robots in an inclusive, collaborative scenario for children with different types of impairments. Our current and future work involves increasing the number of pupils in this study and create an iterative design with teachers and children to improve the robotic system and new learning scenarios. We aim to investigate the potential of tangible robots for new modalities of collaborative learning suitable to any visual impairment and across a range of curricular disciplines. Finally, we plan to test new design iterations, in ecological and long-term settings.

\section{ACKNOWLEDGEMENTS}

We would like to thank the staff and children of Centro Helen Keller for their participation, support, and understanding through these studies. We also like to thank Dra Filipa Correia for her help during the study.

This work has been partially supported by the Swiss National Science Foundation through the National Centre of Competence in Research Robotics and was also supported by national funds through FCT, Fundação para a Ciência e a Tecnologia, under project UIDB/50021/2020.

\section{SELECTION AND PARTICIPATION OF CHILDREN}

All the children and school staff were selected from a local inclusive school and accepted to participate in the study. Parents and school staff gave their informed consent for all the sessions, including video recording and photographs, and the use for academic purposes. Children gave their assent and told they could stop the experiment at any time. The local university ethical committee approved the study and the methodology.

\section{REFERENCES}

[1] Alves-Oliveira, P., Sequeira, P., Melo, F.S., Castellano, G. and Paiva, A. 2019. Empathic robot for group learning: A field study. ACM Transactions on Human-Robot Interaction (THRI). 8, 1 (2019), 134.

[2] Asselborn, T., Guneysu, A., Mrini, K., Yadollahi, E., Ozgur, A., Johal, W. and Dillenbourg, P. 2018. Bringing Letters to Life: Handwriting with Hapticenabled Tangible Robots. Proceedings of the 17th ACM Conference on Interaction Design and Children (New York, NY, USA, 2018), 219-230.

[3] Barros, R.P., Burlamaqui, A.M.F., de Azevedo, S.O., de Lima Sa, S.T., Goncalves, L.M.G., da Silva, A.A.R.S. and others 2017. Cardbot-assistive technology for visually impaired in educational robotics: Experiments and results. IEEE Latin America Transactions. 15, 3 (2017), 517-527.

[4] Belpaeme, T., Kennedy, J., Ramachandran, A., Scassellati, B. and Tanaka, F. 2018. Social robots for education: A review. Science Robotics. 3, 21 (2018). DOI:https://doi.org/10.1126/scirobotics.aat5954.

[5] van den Berghe, R., Verhagen, J., Oudgenoeg-Paz, O., van der Ven, S. and Leseman, P. 2019. Social robots for language learning: A review. Review of Educational Research. 89, 2 (2019), 259-295.

[6] Brule, E., Bailly, G., Brock, A., Valentin, F., Denis, G. and Jouffrais, C. 2016. MapSense: Multi-sensory interactive maps for children living with visual impairments. Conference on Human Factors in 
Computing Systems - Proceedings. (2016), 445-457. DOI:https://doi.org/10.1145/2858036.2858375.

[7] Burnard, P., Gill, P., Stewart, K., Treasure, E. and Chadwick, B. 2008. Analysing and presenting qualitative data. Bdj. 204, (Apr. 2008), 429.

[8] Chandra, S., Dillenbourg, P. and Paiva, A. 2019. Children Teach Handwriting to a Social Robot with Different Learning Competencies. International Journal of Social Robotics. November (2019). DOI:https://doi.org/10.1007/s12369-019-00589-w.

[9] Dementyev, A., Kao, H.-L. (Cindy), Choi, I., Ajilo, D., Xu, M., Paradiso, J.A., Schmandt, C. and Follmer, S. 2016. Rovables: Miniature On-Body Robots As Mobile Wearables. Proceedings of the 29th Annual Symposium on User Interface Software and Technology (New York, NY, USA, 2016), 111-120.

[10] Dillenbourg, P. 1999. What do you mean by collaborative learning? Collaborative-learning: Cognitive and Computational Approaches. P. Dillenbourg, ed. Oxford: Elsevier. 1-19.

[11] Dillenbourg, P., Baker, M.J., Blaye, A. and O'Malley, C. 1995. The evolution of research on collaborative learning. Learning in Humans and Machine: Towards an interdisciplinary learning science. Spada, E., Reiman, and P., eds. Elsevier, Oxford. 189-211.

[12] Ducasse, J., Macé, M., Oriola, B. and Jouffrais, C. 2018. BotMap: Non-Visual Panning and Zooming with an Actuated Tabletop Tangible Interface. ACM Transactions on Computer-Human Interaction (TOCHI). 25, 4 (2018), 24.

[13] Efthymiou, E. and Kington, A. 2017. The development of inclusive learning relationships in mainstream settings: A multimodal perspective. Cogent Education. 4, 1 (2017), 1304015.

[14] Florian, L. 2008. INCLUSION: Special or inclusive education: future trends. British Journal of Special Education. $\quad 35, \quad 4 \quad$ (2008), 202-208. DOI:https://doi.org/10.1111/j.14678578.2008.00402.x.

[15] Guinness, D., Muehlbradt, A., Szafir, D. and Kane, S.K. 2018. The Haptic Video Player: Using Mobile Robots to Create Tangible Video Annotations. Proceedings of the 2018 ACM International Conference on Interactive Surfaces and Spaces (2018), 203-211.

[16] Guneysu Ozgur, A., Özgür, A., Asselborn, T., Johal, W., Yadollahi, E., Bruno, B., Skweres, M. and Dillenbourg, P. 2020. Iterative Design and Evaluation of a Tangible Robot-Assisted Handwriting Activity for Special Education. Frontiers in Robotics and Al. 7, (2020), 29.

[17] Johal, W., Andersen, S., Chevalier, M., Ozgur, A., Mondada, F. and Dillenbourg, P. 2019. Learning symmetry with tangible robots. International Conference on Robotics and Education RiE 2017 (2019), 270-283.
[18] Kennedy, J., Baxter, P. and Belpaeme, T. 2015. The robot who tried too hard: Social behaviour of a robot tutor can negatively affect child learning. 2015 10th ACM/IEEE International Conference on HumanRobot Interaction (HRI) (2015), 67-74.

[19] Lazar, J., Feng, J.H. and Hochheiser, H. 2017. Research methods in human-computer interaction. Morgan Kaufmann.

[20] Meier, A., Spada, H. and Rummel, N. 2007. A rating scheme for assessing the quality of computersupported collaboration processes. International Journal of Computer-Supported Collaborative Learning. 2, 1 (Mar. 2007), 63-86. DOI:https://doi.org/10.1007/s11412-006-9005-x.

[21] Metatla, O. 2017. Uncovering Challenges and Opportunities of Including Children with Visual Impairments in Mainstream Schools. Proceedings of the 31st British Computer Society Human Computer Interaction Conference (Swindon, UK, 2017), 102:1-102:6.

[22] Metatla, O., Serrano, M., Jouffrais, C., Thieme, A. Kane, S., Branham, S., Brulé, É. and Bennett, C.L. 2018. Inclusive Education Technologies: Emerging Opportunities for People with Visual Impairments. Extended Abstracts of the $2018 \mathrm{CHI}$ Conference on Human Factors in Computing Systems (New York, NY, USA, 2018), W13:1--W13:8.

[23] Milne, L.R., Bennett, C.L., Ladner, R.E. and Azenkot, S. 2014. BraillePlay: Educational Smartphone Games for Blind Children. Proceedings of the 16th International ACM SIGACCESS Conference on Computers \& Accessibility (New York, NY, USA, 2014), 137-144.

[24] Milne, L.R. and Ladner, R.E. 2018. Blocks4All: overcoming accessibility barriers to blocks programming for children with visual impairments. Proceedings of the $2018 \mathrm{CHI}$ Conference on Human Factors in Computing Systems (2018), 1-10.

[25] Mitiku, W., Alemu, Y. and Mengsitu, S. 2014 Challenges and opportunities to implement inclusive education. Asian Journal of Humanity, Art and Literature. 1, 2 (2014), 118-135.

[26] Motoyoshi, T., Tetsumura, N., Masuta, H., Oshima, T., Kawakami, H. and others 2016. Tangible programming gimmick using RFID systems considering the use of visually impairments. International Conference on Computers Helping People with Special Needs (2016), 51-58.

[27] Mynatt, E.D. 1997. Transforming Graphical Interfaces into Auditory Interfaces for Blind Users. Hum.-Comput. Interact. 12, 1 (Mar. 1997), 7-45. DOI:https://doi.org/10.1207/s15327051hci1201\&2_2

[28] Mynatt, E.D. and Weber, G. 1994. Nonvisual presentation of graphical user interfaces: contrasting two approaches. Proceedings of the SIGCHI Conference on Human Factors in Computing 
Systems (1994), 166-172.

[29] Özgür, A., Johal, W., Mondada, F. and Dillenbourg, P. 2017. Haptic-Enabled Handheld Mobile Robots: Design and Analysis. Proceedings of the $2017 \mathrm{CHI}$ Conference on Human Factors in Computing Systems (New York, NY, USA, 2017), 2449-2461.

[30] Özgür, A., Johal, W., Mondada, F. and Dillenbourg, P. 2017. Windfield: learning wind meteorology with handheld haptic robots. Proceedings of the 2017 ACM/IEEE International Conference on HumanRobot Interaction (2017), 156-165.

[31] Özgür, A., Lemaignan, S., Johal, W., Beltran, M., Briod, M., Pereyre, L., Mondada, F. and Dillenbourg, P. 2017. Cellulo: Versatile handheld robots for education. 2017 12th ACM/IEEE International Conference on Human-Robot Interaction (HRI (2017), 119-127.

[32] Plimmer, B., Crossan, A., Brewster, S.A. and Blagojevic, R. 2008. Multimodal Collaborative Handwriting Training for Visually-impaired People. Proceedings of the SIGCHI Conference on Human Factors in Computing Systems (New York, NY, USA, 2008), 393-402.

[33] Reid, P. and Plimmer, B. 2008. A Collaborative Multimodal Handwriting Training Environment for Visually Impaired Students. Proceedings of the 20th Australasian Conference on Computer-Human Interaction: Designing for Habitus and Habitat (New York, NY, USA, 2008), 195-202.

[34] Scassellati, B., Boccanfuso, L., Huang, C.-M., Mademtzi, M., Qin, M., Salomons, N., Ventola, P. and Shic, F. 2018. Improving social skills in children with ASD using a long-term, in-home social robot. Science Robotics. 3, 21 (2018), eaat7544.

[35] Tanhua-Piiroinen, E., Pasto, V., Raisamo, R. and Sallnäs, E.-L. 2008. Supporting Collaboration between Visually Impaired and Sighted Children in a Multimodal Learning Environment. Haptic and Audio Interaction Design (Berlin, Heidelberg, 2008), 11-20.

[36] Thieme, A., Brulé, E., Bennett, C., Serrano, M. Jouffrais, C. and Metatla, O. 2019. Toward classroom experiences inclusive of students with disabilities. Interactions. 26, 1 (2019), 41-45. DOI:https://doi.org/10.1145/3289485.

[37] Thieme, A., Morrison, C., Villar, N., Grayson, M. and Lindley, S. 2017. Enabling Collaboration in Learning Computer Programing Inclusive of Children with Vision Impairments. Proceedings of the 2017 Conference on Designing Interactive Systems (New York, NY, USA, 2017), 739-752.

[38] Thill, S., Pop, C.A., Belpaeme, T., Ziemke, T. and Vanderborght, B. 2013. Robot-Assisted Therapy for Autism Spectrum Disorders with (Partially) Autonomous Control: Challenges and Outlook Paladyn, Journal of Behavioral Robotics. 3, 4 (2013). DOI:https://doi.org/10.2478/s13230-013-0107-7.
Thinus-Blanc, C. and Gaunet, F. 1997.
Representation of space in blind persons: vision as a spatial sense? Psychological bulletin. 121, 1 (1997), 20.

[40] Weil, M.J. and Cunningham Amundson, S.J. 1994 Relationship Between Visuomotor and Handwriting Skills of Children in Kindergarten. American Journal of Occupational Therapy. 48, 11 (1994), 982-988. DOI:https://doi.org/10.5014/ajot.48.11.982.

[41] Winberg, F. and Bowers, J. 2004. Assembling the Senses: Towards the Design of Cooperative Interfaces for Visually Impaired Users. Proceedings of the 2004 ACM Conference on Computer Supported Cooperative Work (New York, NY, USA, 2004), 332-341.

[42] Zijp-Rouzier, S. and Petit, E. 2005. Teaching geometry to visually impaired pupils using haptics and sound. Proceedings of $\mathrm{HCl}$ (2005). 